\title{
Extraction and Determination of Anti-0xidant Activity of Polyphenols from Carrot Pomace, and Their Use in Date Oat Bar
}

\author{
Hammad Naeem ${ }^{1 *}$, Umar Niaz ${ }^{2}$, Sarmad Sattar ${ }^{1}$ and Hira Ijaz ${ }^{1}$ \\ ${ }^{1}$ National Institute of Food Science and Technology, University of Agriculture Faislabad, Pakistan
}

${ }^{2}$ Department of Entomology, Pakistan

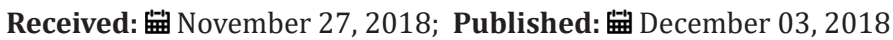

*Corresponding author: Hammad Naeem, National Institute of Food Science and Technology, Pakistan

\begin{abstract}
Carrot pomace has polyphenols in large amounts. Polyphenols play an important role in the prevention of degenerative diseases such as cancer and cardiovascular diseases. Carrot pomace goes to waste with all these useful compounds. Carrot pomace or its extract can be utilized in food products to combat food shortage. Extraction of molecules from biological materials by conventional techniques, such as simple maceration, is time consuming. Sonication breaks the cell membranes. It reduces considerably the extraction time and increasing the extract yield. These phenolics were extracted using conventional Maceration techniques \& advance Sonication technique. The extracts were used in Functional date-oat bars. Bars were then tested for determination of total phenolics present in them. Total Polyphenol content of functional date bar having 1\% extract were 3.160 mg GAE/g of extract. Antioxidant activity in terms of \% inhibition of functional date bar having $1 \%$ extract is $26.70 \%$. It is evident from the results that the extracts of carrot pomace contain significant number of polyphenols and anti-oxidant activity. The potential of reducing waste to combat the food security issues are high, as it is estimated that by $50 \%$ reduction in current food waste, the world would be saving 1314 trillion kcal per year. This represent a reduction of about $22 \%$ of the number of additional calories needed to feed the projected population by 2050 .
\end{abstract}

\section{Introduction}

The carrot belongs to the family Apiaceae. The carrot originated in Asia. Carrots are particularly rich in carotene (pro-vitamin A) and also significant amount of polyphenols. Carrots are also known to have polyphenols and antioxidants. Carrots are consumed either fresh, as a salad crop, or cooked. Large quantities are also processed, either alone or in mixtures with other vegetables, by canning or freezing. Polyphenols are a group of chemical substances found in plants. Polyphenols are naturally present in plants. Polyphenols are not essential nutrients meaning that they are not required by the human body for sustaining life, but they can exert beneficial functions [1]. Fruits and vegetables are sources of polyphenols. Polyphenols play an important role in the prevention of degenerative diseases such as cancer and cardiovascular diseases. Polyphenols are antioxidants. Antioxidants are the substances that prevent oxidation. Antioxidants, polyphenols and carotenoids, may help protect cells from damage caused by free radicals. Extraction of molecules from biological materials by conventional

techniques, such as simple maceration, is time consuming. The development of modern techniques such as extraction assisted by microwave or extraction assisted by ultrasound. Sonication breaks the cell membranes. It reduces considerably the extraction time and increasing the extract yield. The application of ultrasound disrupts the cell wall structures and accelerates diffusion through membranes; thus, the cell lyses and hence facilitates the release of cell contents. The potential of reducing waste to combat the food security issues are high, as it is estimated that by $50 \%$ reduction in current food waste, the world would be saving 1314 trillion kcal per year. This represent a reduction of about $22 \%$ of the number of additional calories needed to feed the projected population by 2050 . By the year 2100 , the global population is expected to increase to 11.2 billion. To feed this projected population and address the food security and the environmental issues, waste reduction and utilization food resources are the important strategies to be developed. The nutritional characterization of waste from fruits 
and vegetables suggest that most of these crop remains and by products can be utilized, recovered and converted into value added food products. Hence, value addition of these wastes through drying technology and extraction methods to dehydrated products and nutraceutical products, respectively could be an alternative market option for the food and the associated industries. We incorporated phenolic extract in date bars so that we can get benefit from their anti-oxidant properties. Date bars have high nutrition value. Consumer prefer date bars that are more tasted followed by proper textural features that could be obtained by equilibrium of ingredients. Antioxidant activity resulting from the presence of phenolic compounds in the bars is well established.

\section{Objectives}

a) To carry out proximate analysis of carrot pomace powder.

b) To determine the polyphenol content of carrot pomace extract.

c) To determine the Antioxidant activity of carrot pomace extract.

d) To produce functional date bars.

\section{Materials and Methods}

The research study was conducted at Food Sciences Research Institute (FSRI), National Agriculture Research Centre (NARC), Islamabad, Pakistan.

a. Selection of vegetables: Carrot vegetable were purchased from local vegetable market, Islamabad and transferred to FSRI, NARC.

b. Preparation of pomace powder: Vegetables were washed thoroughly, juice was extracted, and fresh weight of carrot pomace was taken on calibrated Top load balance. (Seedburo 8800A).

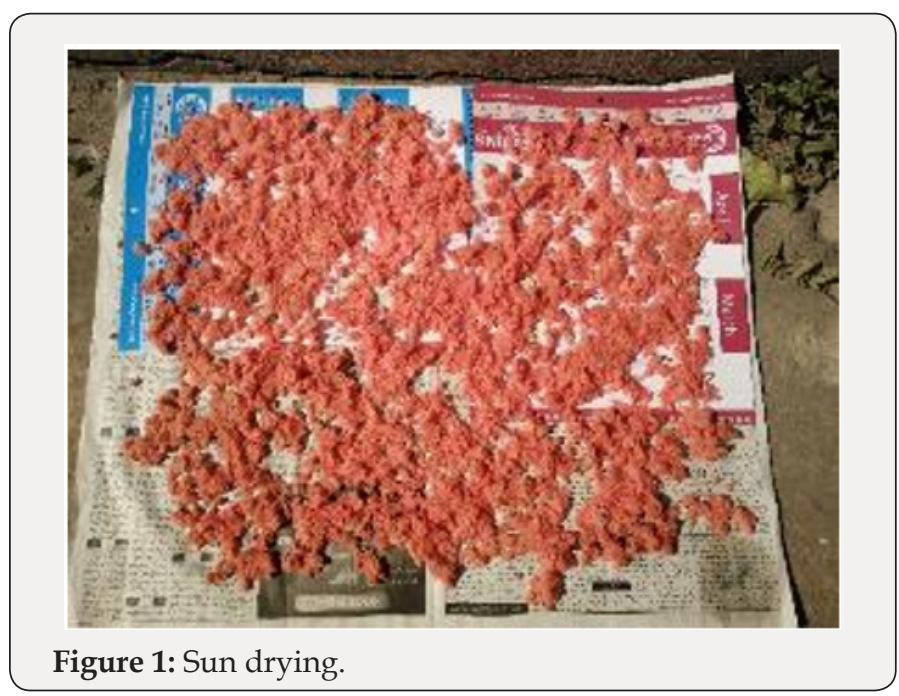

c. Drying of carrot pomace: Carrot pomace were sun dried for 10 hours and then carrot pomace dried in hot air oven (Mermmet
ULM-500) at $500^{\circ} \mathrm{C}$ for 48 hours until moisture content of carrot pomace was reduced to $10 \%$ or below. Dried carrot pomace was weighed on top load balance (Figure 1).

d. Grinding of Carrot Pomace: Dried carrot pomace was grounded to fine powder in a Cyclotech mill with a sieve size 0.5 $\mathrm{mm}$ and weighed.

e. Storage of pomace powder: The pomace powder was packed in air-tight zip bags and stored at refrigeration temperature $40^{\circ} \mathrm{C}$ until further studies (Figure 2).

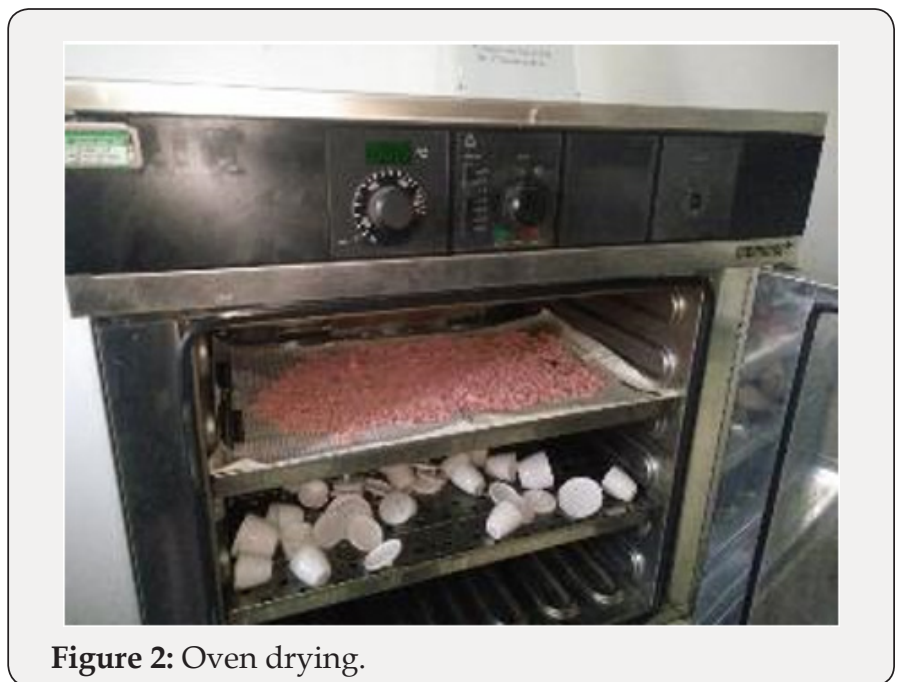

Determination of Moisture Content in Carrot Pomace Powder

\section{Principle}

Sample is weighed and placed in hot air oven with set temperature at $130^{\circ} \mathrm{C}$ for 1 hour (60 minutes). The weight after drying is used to determine moisture content of the sample (Figure $3)$.

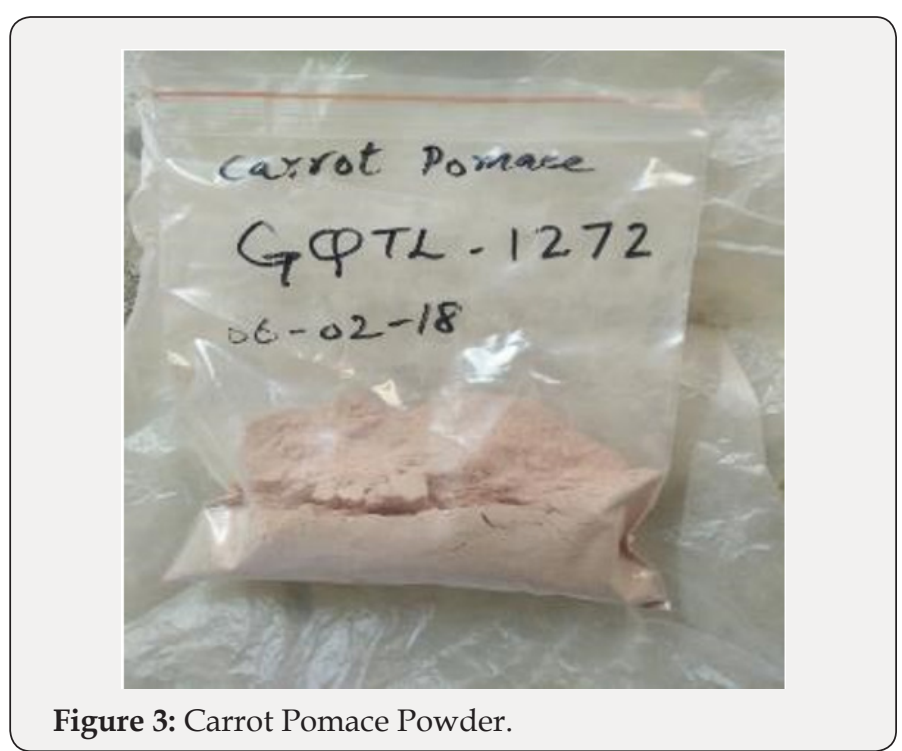




\section{Apparatus:}

i. Hot air oven (Memmert OVEN FML-13)

ii. Moisture dishes

iii. Desiccator

iv. Plastic spatula

v. Analytical weighing balance

\section{Procedure:}

Took two moisture dishes and labelled them. Take $2 \mathrm{~g}$ of carrot pomace powder in these moisture dishes. Note the weight of empty moisture dishes and exact weight of sample taken. Now cover the moisture dishes with lids and transferred them to hot air oven and now uncovered them $[2,3]$. Set the temperature at $130^{\circ} \mathrm{C}$ and note the time when temperature reached at $130^{\circ} \mathrm{C}$. After 1 hour (60 minutes) turned off the oven and put the moisture dishes out from the oven with the help of gloves and covered the dishes with lids. Now place the moisture dishes in desiccator for 15-25minutes (Figures 4-6). After, moisture dishes are cooled to room temperature. Remove the lids and weighed them again (Tables $1 \& 2$ ).
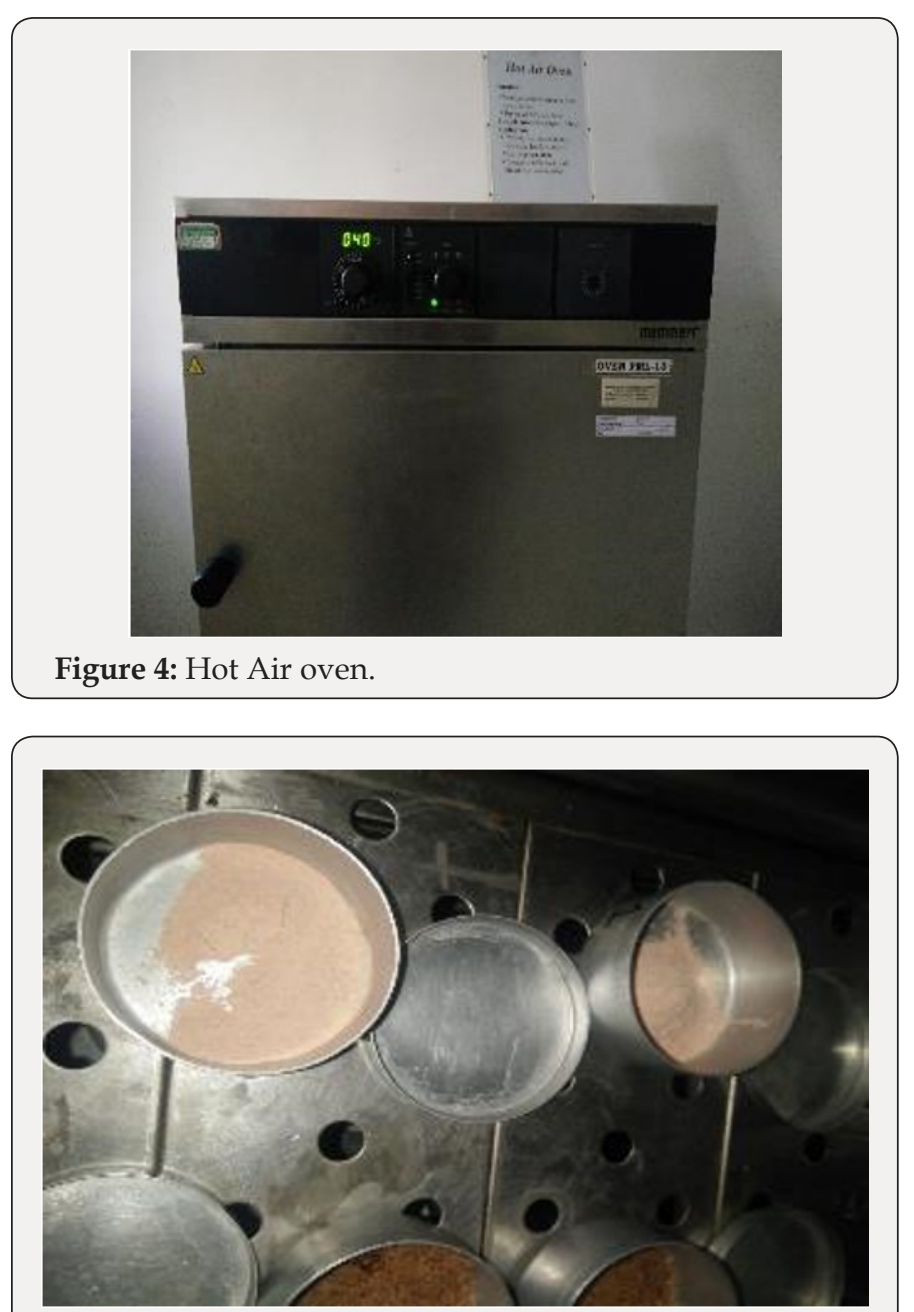

Figure 5: Moisture dishes containing sample.

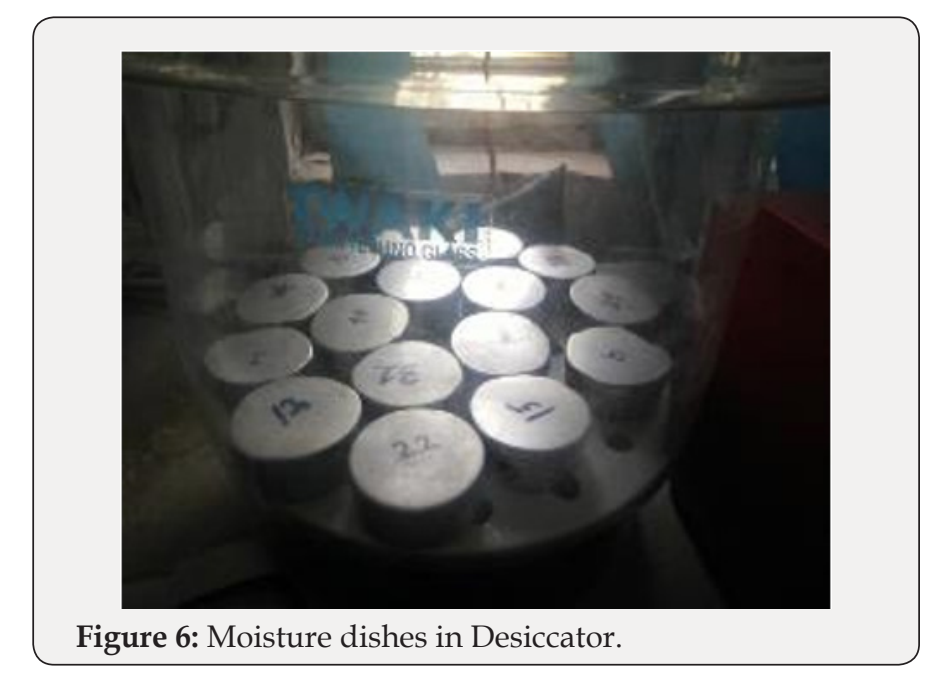

Table 1: Proximate analysis of carrot pomace powder. It is evident from table 2 that Carrot pomace powder has optimum composition as described by other researchers.

\begin{tabular}{|c|c|c|}
\hline Sr. No. & Proximate analysis & Composition (\%) \\
\hline 1. & Moisture & 8.94 \\
\hline 2. & Ash & 5.72 \\
\hline 3. & Fat & 1.34 \\
\hline 4. & Fiber & 16.43 \\
\hline
\end{tabular}

Table 2: Yield of carrot pomace extract. The yield of carrot pomace extract is within range as described by earlier studies.

\begin{tabular}{|c|c|}
\hline Replication & Yield (\%) \\
\hline 1 & 24.14 \\
\hline 2 & 25.67 \\
\hline 3 & 26.09 \\
\hline 4 & 25.88 \\
\hline Mean \pm Std Dev. & $25.45 \pm 0.88$ \\
\hline
\end{tabular}

\section{Calculation:}

$$
\% \text { moisture }=\frac{\text { InitialWeight }- \text { FinalWeight }}{\text { sampleweight }} * 100
$$

\section{Determination of Ash in Carrot Pomace Powder}

\section{Principle:}

At high temperature i.e. $550^{\circ} \mathrm{C}$ all organic compounds are burnt off. Minerals are less volatile than other food compounds and are not destroyed at this high temperature. The inorganic material left behind is called ash (minerals).

\section{Apparatus:}
a. Muffled furnace (CARBOLITE AAF 1100)
b. Crucibles with lids
c. Desiccator
d. Analytical weighing balance 


\section{Procedure:}

Took clean crucibles at room temperature and weighed them without their lids. Now take $3 \mathrm{~g}$ of carrot pomace powder. Note the weight accurately. Now place the lids on the crucibles and transferred them to the Muffled furnace [4]. Set the temperature at $550^{\circ} \mathrm{C}$ and let the sample incinerate for about 18 hours (overnight) until light whitish grey ash was obtained (Figure 7). Carefully remove the crucibles with the help of gloves and place them in Desiccator for 15-25 minutes. When the crucibles have reached room temperature weighed them accurately (Tables 3,4).

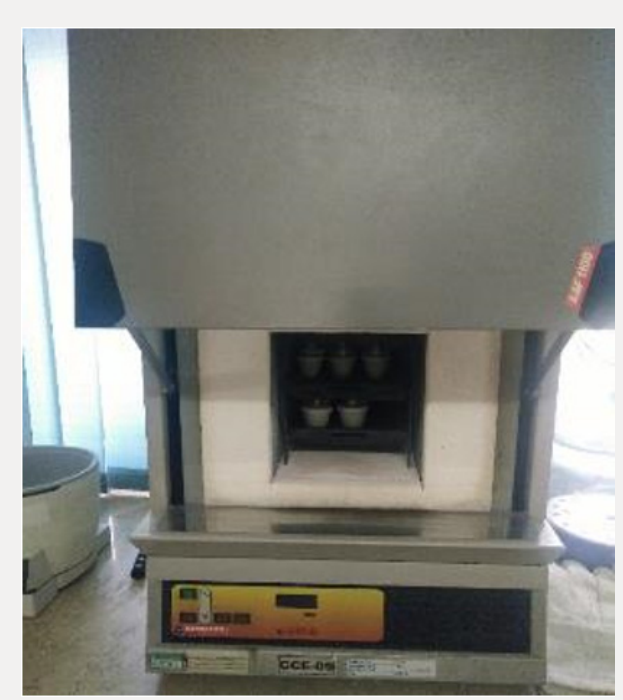

Figure 7: Muffle furnace.

Table 3: Total polyphenols content of carrot pomace extract (ultrasound).

\begin{tabular}{|c|c|c|}
\hline Sample GQTL 1272 & Absorbance (nm) (Y) & Mg GAE/g of extract \\
\hline Rep. 1 & 0.7646 & 17.96 \\
\hline Rep. 2 & 0.6919 & 17.10 \\
\hline Rep. 3 & 0.7358 & 17.89 \\
\hline Rep. 4 & 1.2243 & 22.91 \\
\hline Mean \pm St Dev. & & $18.97 \pm 2.65$ \\
\hline
\end{tabular}

Table 4: Total polyphenols content of carrot pomace extract (Maceration). It is evident from table $4 \& 5$ that Extraction of total Polyphenol content obtained from Maceration technique was $6.11 \%$ higher than Ultrasound assisted extraction. Carrot pomace extract had high enough polyphenols content suitable for further study and preparation of functional foods.

\begin{tabular}{|c|c|c|}
\hline Sample GQTL 1272 & Absorbance(nm) (Y) & Mg GAE/g of extract \\
\hline Rep. 1 & 0.7800 & 20.23 \\
\hline Rep. 2 & 0.9522 & 18.21 \\
\hline Rep.3 & 1.0989 & 21.49 \\
\hline Rep.4 & 1.0099 & 20.6 \\
\hline Mean \pm Std Dev. & & $20.13 \pm 1.38$ \\
\hline
\end{tabular}

\section{Calculation:}

$$
\% \text { Ash }=\frac{\text { FinalWeight }- \text { CrucibleWeight }}{\text { sampleweight }} * 100
$$

Determination of Crude Fiber Content in Carrot Pomace Powder

\section{Principle:}

Crude fiber is insoluble and combustible organic residue that remains after the sample has been treated under known conditions i.e. $0.25 \mathrm{~N}$ Sulphuric acid and $40.7 \% \mathrm{NaOH}$ solution.

\section{Materials and Apparatus:}
A. Sulphuric acid $0.25 \mathrm{~N}$
B. Sodium hydroxide $407 \mathrm{~g} / \mathrm{L}(40.7 \%)$
C. Distilled water
D. Crude fiber Digestion apparatus
E. Muslin cloth
F. Oven
G. Muffled furnace
H. Measuring cylinders
I. Beakers

\section{Procedure:}

Table 5: DPPH scavenging activity of polyphenols of carrot pomace extract (Ultrasound).

\begin{tabular}{|c|c|c|c|}
\hline $\begin{array}{c}\text { Sample } \\
\text { GQTL 1272 }\end{array}$ & $\begin{array}{c}\text { Concentration }(\boldsymbol{\mu g} / \\
\mathbf{m L})\end{array}$ & Absorbance(nm) & $\begin{array}{c}\text { Inhibition } \\
\text { (\%) }\end{array}$ \\
\hline Conc. 1. & 400 & 0.8210 & 45.68 \\
\hline Conc. 2. & 200 & 0.8220 & 26.01 \\
\hline Conc. 3. & 100 & 0.8428 & 15.93 \\
\hline Conc. 4. & 50 & 0.8474 & 8.38 \\
\hline
\end{tabular}

Table 6: DPPH Scavenging activity of polyphenols of carrot pomace extract (maceration). It is evident from table $6 \& 7$ that as the concentration of the Extract is decreased, the inhibition also decreases with slowed the decrease in antioxidant activity of carrot pomace extract.

\begin{tabular}{|c|c|c|c|}
\hline $\begin{array}{c}\text { Sample } \\
\text { GQTL 1272 }\end{array}$ & $\begin{array}{c}\text { Concentration }(\boldsymbol{\mu g} / \\
\mathbf{m L})\end{array}$ & Absorbance(nm) & $\begin{array}{c}\text { Inhibition } \\
\text { (\%) }\end{array}$ \\
\hline Conc. 1. & 400 & 0.9154 & 47.22 \\
\hline Conc. 2. & 200 & 0.7472 & 28.12 \\
\hline Conc. 3. & 100 & 0.8159 & 15.02 \\
\hline Conc. 4. & 50 & 0.7921 & 9.56 \\
\hline
\end{tabular}

Weighed an empty crucible. Weighed $2 \mathrm{~g}$ of sample in crucible. Put the sample in beaker. Added 200mL Sulphuric acid. Boiled for 30 minutes. Turned off the heat and add $10 \mathrm{ml}$ of sodium hydroxide. 
Boiled for another 30 minutes. Removed and filtered through muslin cloth(Tables 5 \& 6). Washed the residue with hot distilled water to remove excess of alkali. Dried the crucible with residue at $130^{\circ} \mathrm{C}$ for 1 hour [5]. Let it cool and weighed (A). Ignited the residues at $600^{\circ} \mathrm{C}$ in muffled furnace overnight (Figure 8).

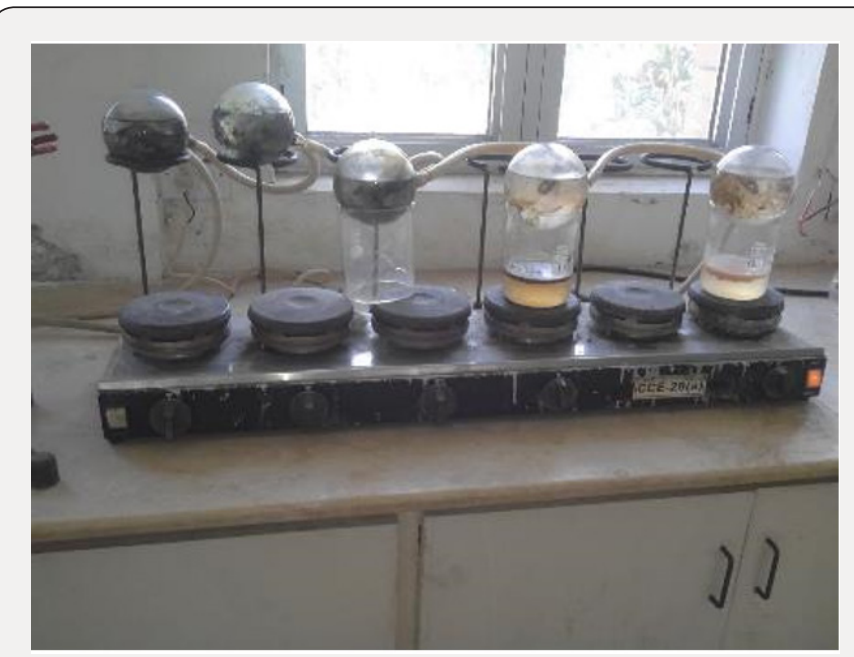

Figure 8: Crude fiber digestion apparatus.

Weight of crucible + Sample after drying (A)

Weight of crucible + Sample after ashing (B)

\section{Calculations:}

$$
\% \text { Crudefiber }=\frac{A-B}{\text { sampleweight }} * 100
$$

\section{Determination of Fat Content in Carrot Pomace Powder}

\section{Principle:}

The fat (triglycerides) can be determined by extracting the samples with suitable solvent e.g. hexane, petroleum ether etc. in a continuous extraction apparatus. Solvent is recollected, and remaining fat is oven dried and weighed.

\section{Material and Apparatus:}
a) Analytical balance
b) Buchi apparatus system (B-740)
c) Beakers
d) Cellulose Thimble
e) Desiccator
f) Oven
g) $n$ hexane

\section{Procedure:}

$3 \mathrm{~g}$ of sample was weighed in to thimble and covered with tissue paper. Buchi classical beakers were dried at $105^{\circ} \mathrm{C}$ for 30 minutes.
Cooled and weighed $\left(\mathrm{W}_{1}\right) \cdot 35-40 \mathrm{~mL}$ of solvent was added. Thimble and beaker were fixed in apparatus. Boiling position was set for 45 minutes. Rinsing position was set for 35 minutes (Figure 9). The solvent was collected by blocking the extraction outlet. Beaker with fat was dried at $105^{\circ} \mathrm{C}$ for 30 minutes and cooled in desiccator and weighed $\left(\mathrm{W}_{2}\right)$ (Tables 7 \& 8).

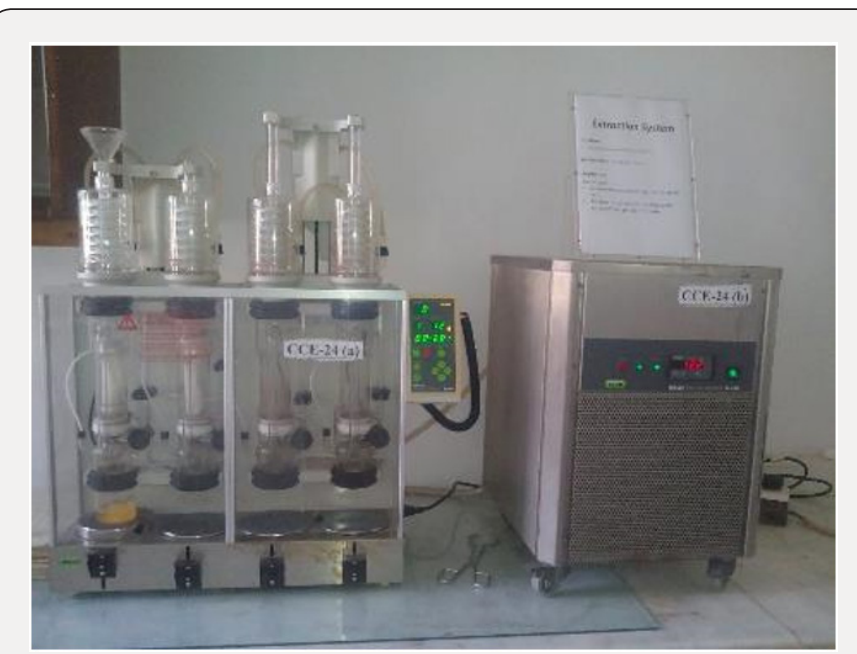

Figure 9: Soxhlet apparatus.

Table 7: Proximate analysis of functional date bars.

\begin{tabular}{|c|c|c|c|c|}
\hline Treatment & Moisture\% & Ash\% & Fat\% & Fiber\% \\
\hline $\mathrm{T}_{0}$ (control) & 17.11 & 19.95 & 10.56 & 1.81 \\
\hline $\mathrm{T}_{1}(1 \%)$ & 17.07 & 20.42 & 10.33 & 1.66 \\
\hline $\mathrm{T}_{2}(3 \%)$ & 17.00 & 21.04 & 10.72 & 1.47 \\
\hline
\end{tabular}

Table 8: Sensory Evaluation of functional date bar. It is clear from the table 13 that treatment T2 ( $3 \%$ extract supplementation) was preferred over others and got the highest sensory score while control date bars were least liked and obtained the lowest sensory score.

\begin{tabular}{|c|c|c|c|c|c|}
\hline Sample & Color & Taste & Flavor & Texture & $\begin{array}{c}\text { Overall } \\
\text { acceptability }\end{array}$ \\
\hline Control $\left(\mathrm{T}_{0}\right)$ & 7.20 & 6.60 & 6.60 & 6.20 & 6.40 \\
\hline $\mathrm{T}_{1}(1 \%)$ & 7.00 & 6.80 & 7.00 & 6.40 & 6.80 \\
\hline $\mathrm{T}_{2}(3 \%)$ & 7.60 & 7.80 & 7.80 & 7.20 & 7.80 \\
\hline
\end{tabular}

Calculation:

$$
\% \text { Fat }=\frac{W_{1}-W_{2}}{\text { sampleweight }} * 100
$$

\section{Extraction of Polyphenols}

\section{Ultrasound-Assisted Extraction}

\section{Principle:}

Sonicator produces ultrasonic waves which break the sample at molecular level. The solvent penetrates the sample and polyphenols are dissolved in the solvent. 


\section{Apparatus:}
i. Sonicator
ii. Beakers
iii. Reagent bottles
iv. Glass funnels
v. Whatman filter paper 41
vi. Aluminum foils
vii. Round Bottom flasks
viii. Volumetric cylinder

\section{Chemicals:}
a) Ethanol (50\% solution)
b) Methanol (50\% solution)

\section{Procedure:}

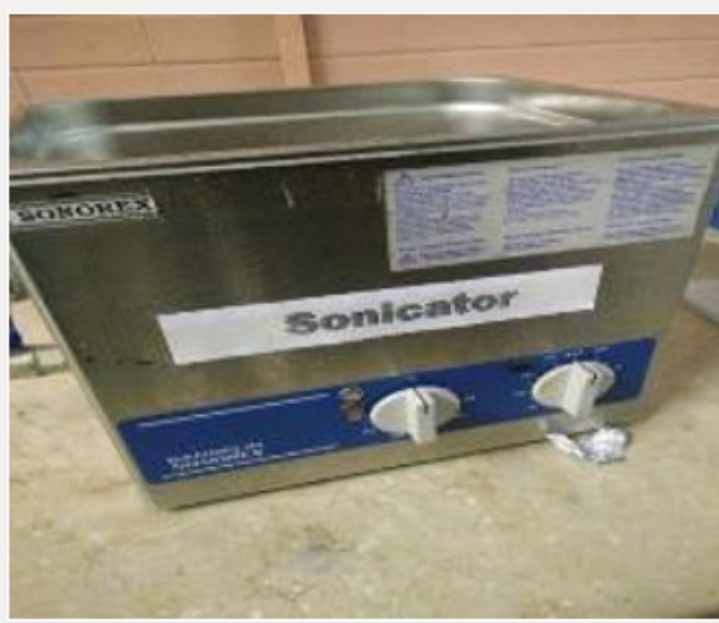

Figure 10: Sonicator.

Table 9: Determination of Total Polyphenol Content of functional date bars. It is evident from table no. 9 that polyphenol content of functional date bar having $3 \%$ extract is more than the functional date bar having $1 \%$ extract.

\begin{tabular}{|c|c|c|}
\hline Sample & Absorbance & mg GAE/g of extract \\
\hline $\mathrm{T}_{0}$ (control) & 0.4151 & 1.542 \\
\hline $\mathrm{T}_{1}(1 \%)$ & 0.4746 & 3.160 \\
\hline $\mathrm{T}_{2}(3 \%)$ & 0.5932 & 5.075 \\
\hline
\end{tabular}

Carefully weighed $3 g$ carrot pomace powder and put it in each of the 4 reagent bottles $(125 \mathrm{~mL})$. In 2 reagent bottles put $50 \%$ ethanol solution and in 2 reagent bottles was added $50 \%$ methanol solution. Sample to solvent ratio must be 1:20 [6]. Reagent bottles were closed tightly with their lids (Figure 10). Distill water was added in sonicator up to optimum level. Reagent bottles were carefully placed in sonicator. Sonicator was turned on for 1 hour at $50^{\circ} \mathrm{C}$. After 1-hour reagent bottles were taken out from sonicator and cooled to room temperature (Tables $9 \& 10$ ).

Table 10: Determination of Antioxidant activity of functional date bar. It is clear from table no. 10 that anti-oxidant activity of functional date bar having 3\% extract is almost 2 times higher than the functional date bar having $1 \%$ extract.

\begin{tabular}{|c|c|c|}
\hline Sample & Absorbance & Inhibition\% \\
\hline $\mathrm{T}_{0}$ (control) & 0.8240 & 14.98 \\
\hline $\mathrm{T}_{1}(1 \%)$ & 0.8073 & 26.70 \\
\hline $\mathrm{T}_{2}(3 \%)$ & 0.2451 & 41.63 \\
\hline
\end{tabular}

\section{Filtration:}

\section{Procedure:}

4 round bottom flasks were placed on their respective supports. Samples from sonicator were filtered into round bottom flasks using whatman filter paper no.41.

\section{Solvent extraction:}

\section{Apparatus:}
A. Rotary evaporator (BUCHI B-490)
B. Circulating chillier
C. Vacuum controller
D. Hot air oven
E. Beakers
F. Aluminum foil

\section{Procedure:}

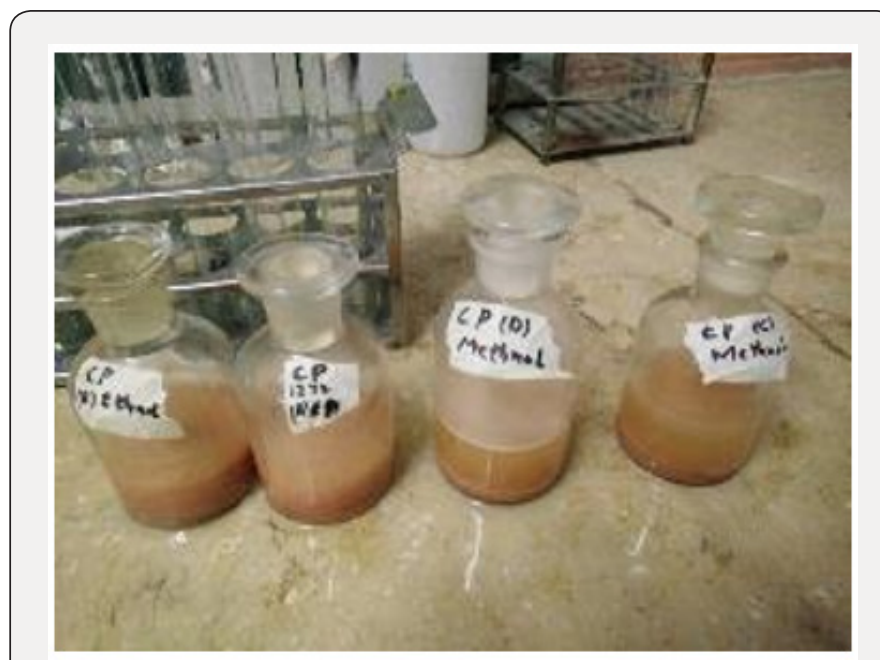

Figure 11: Reagents Bottles containing sample.

Distilled water was added in water bath to optimum level. Water bath temperature was set at $50^{\circ} \mathrm{C}$. Chiller was turned on and its temperature was set at $20^{\circ} \mathrm{C}$. Pressure of vacuum controller was set at $120 \mathrm{mbar}$. Round bottom flask was attached with condenser 
and rotator. Rotation was turned on. Solvent was evaporated and condensed in the condenser and collected in collection chamber. Solvent was evaporated until $10 \mathrm{~mL}$ of sample remained. This procedure was repeated for each round bottom flask containing sample. Remaining extract of carrot pomace powder was collected in $30 \mathrm{~mL}$ beakers (Figure 11). These beakers were placed in hot air oven at $45^{\circ} \mathrm{C}$ for 16 hours to completely evaporate remaining water. Each of the beaker was covered with aluminum foil and placed in refrigerator till further analysis.

\section{Maceration Extraction Technique:}

\section{Principle:}

Solution containing sample is placed in shaking water bath for 22 hours at $40^{\circ} \mathrm{C}$. Shaking water bath agitates the sample thus, enhancing the extraction of polyphenols.

\section{Apparatus and Chemicals:}
a. Shaking water bath
b. Ethanol (50\% solution)
c. Methanol (50\% solution)
d. Carrot pomace powder
e. Analytical Balance (Model 8800A)
f. Conical Flasks
g. Aluminum foil

\section{Procedure:}

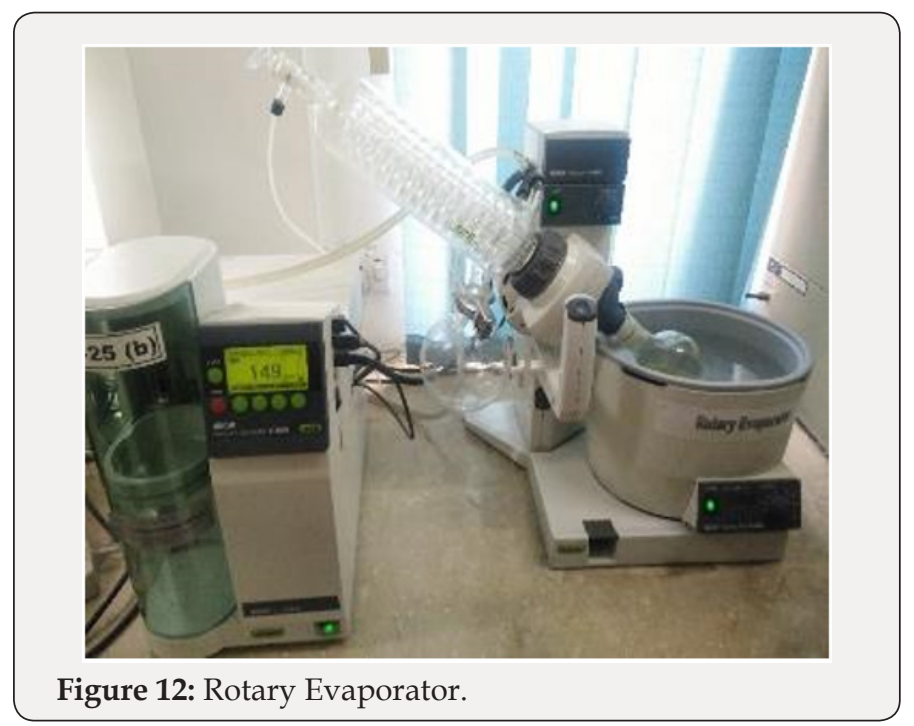

4 conical flasks were taken and $3 \mathrm{~g}$ of carrot pomace powder was weighed in each of them. $45 \mathrm{~mL}$ of $50 \%$ ethanol solution was added in 2 conical flasks and $45 \mathrm{~mL}$ of $50 \%$ methanol solution was added in remaining 2 flasks. Each of these conical flasks were covered with aluminum foils and were tightened by using rubber bands. Shaking water bath was filled with distilled water to optimum level [7]. Conical flasks were placed in shaking water bath for 22 hours at $40^{\circ} \mathrm{C}$. Filtration, solvent extraction and pomace extract were stored by the same procedure described above for ultrasound-assisted extraction (Figure 12).

\section{Determination of Total Polyphenol Content}

The total polyphenol content of carrot pomace powder was determined by Folin-Ciocalteu method as explained by Singleton (1999). Gallic acid standard solutions were prepared at different concentrations $(12.5,25,50,100,200,400 \mu \mathrm{g} / \mathrm{mL})$. Ethanolic solution of sample extract $10 \mathrm{mg} / \mathrm{mL}$ was prepared for the analysis. $0.5 \mathrm{~mL}$ ethanolic solution was mixed with $2.5 \mathrm{~mL}$ of $10 \%$ folinciocalteu's reagent dissolved in water and $2.5 \mathrm{~mL} 7.5 \% \mathrm{Na} 2 \mathrm{Co}$. Blank was simultaneously prepared, containing $0.5 \mathrm{~mL}$ ethanol, $2.5 \mathrm{~mL}$ diluted Folin-ciocalteu reagent dissolved in water and $2.5 \mathrm{~mL}$ $7.5 \% \mathrm{Na}_{2} \mathrm{Co}_{3}$. Then the sample was incubated at $25^{\circ} \mathrm{C}$ for 30 minutes. The calibration curve was prepared from various concentrations of Gallic acid standard solutions (Figure 13). The absorbance was determined at $765 \mathrm{~nm}$ with UV-visible Spectrophotometer. The total polyphenol contents were expressed as mg Gallic acid equivalent (GAE)/g of extract.

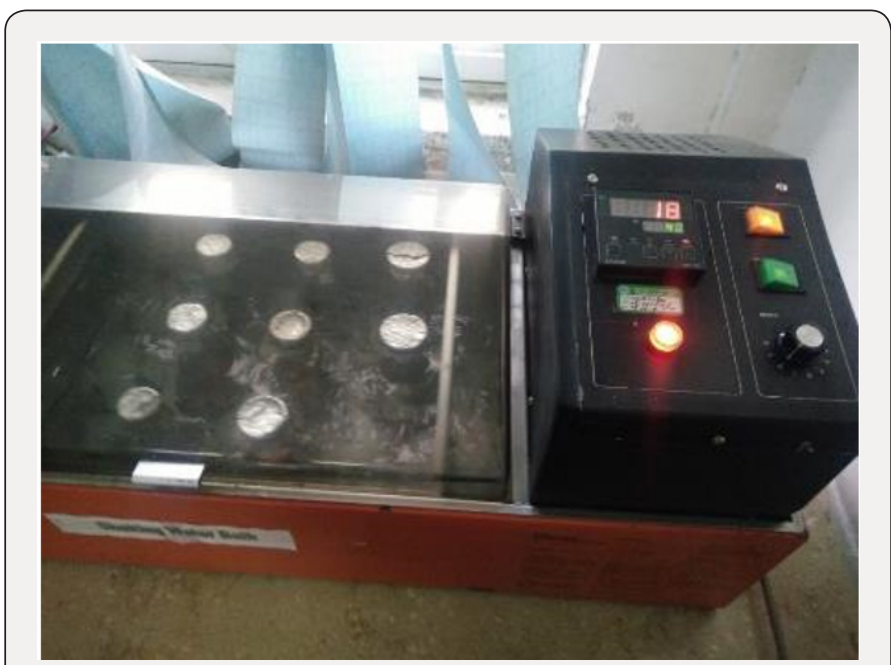

Figure 13: Shaking Water Bath.

Determination of Antioxidant Activity of Carrot Pomace Powder

Anti-oxidant activity of carrot pomace extract was determined by DPPH (1, 1-diphenyl-2-picryl-hydrazyl) radical scavenging assay according to method of Brand William et al. (1995) with some modifications. The DPPH Stock Solution was prepared by dissolving $0.006 \mathrm{~g}$ of DPPH with $25 \mathrm{~mL}$ of methanol. Carrot pomace extract of concentrations $400 \mu \mathrm{g} / \mathrm{ml}, 200 \mu \mathrm{g} / \mathrm{ml}, 100 \mu \mathrm{g} / \mathrm{ml}, 50 \mu \mathrm{g} /$ $\mathrm{ml}$ were prepared $[8,9]$. The working solution was obtained DPPH solution with methanol to obtain an absorbance of 0.9921 at $517 \mathrm{~nm}$ using UV-visible spectrophotometer (Figure 14). $3 \mathrm{~mL}$ from above mentioned working DPPH solution was mixed with $200 \mu \mathrm{L}$ of the samples at different concentrations $(50-400 \mu \mathrm{g} / \mathrm{mL})$. The solution in the test tubes were shaken well and incubated in dark for 15 minutes at room temperature. Absorbance for all the test tubes was 
taken at $517 \mathrm{~nm}$. The Scavenging activity was estimated based on the percentage of DPPH radical.

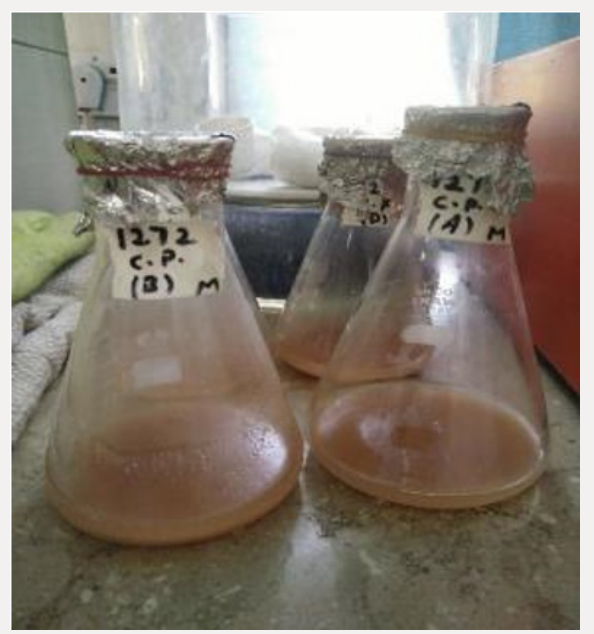

Figure 14: Conical Flask containing sample.

\section{Preparation of Functional Date Bars}

Ingredients:

\section{A. For Control:}
i. Dates: $60 \%$
ii. Oats: $20 \%$
iii. Almonds: $16 \%$
iv. Coconut oil: $4 \%$

B. For $T_{1}(1 \%)$ :
i. Dates: $59 \%$
ii. Oats: $20 \%$
iii. Almonds: $16 \%$
iv. Coconut oil: $4 \%$
v. Extract: $1 \%$

C. For $\mathrm{T}_{2}(3 \%)$ :
i. Dates: $\mathbf{5 7 \%}$
ii. Oats: $20 \%$
iii. Almonds: $16 \%$
iv. Coconut oil: $4 \%$
v. Extract: $3 \%$

\section{Preparation:}

Almonds and oats were ground well in a grinder. Carrot extract were added at different ratio $(1 \%, 3 \%)$. Dates were added into the grinder. Coconut oil was added into the grinder. All the ingredients were ground well. Transferred all the mixture into tray and placed the tray into refrigerator for 10 minutes. Removed tray out from refrigerator and cut the mixture into bars of $7.5 \mathrm{~cm}$ length, $2.5 \mathrm{~cm}$ width, $1 \mathrm{~cm}$ height. Bars were packed in butter paper.

\section{Sensory Evaluation of Functional Date Bars:}
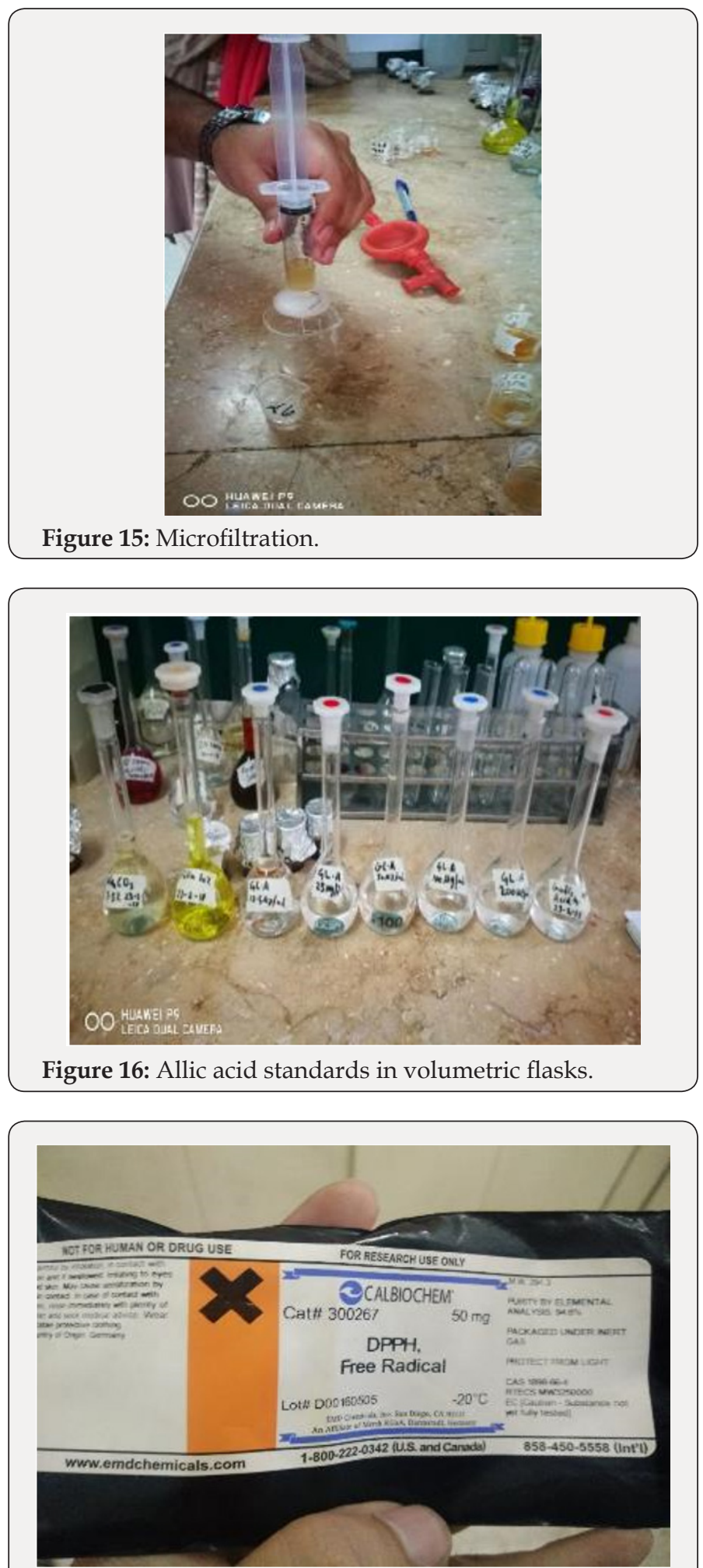

Figure 17: DPPH Free Radical. 


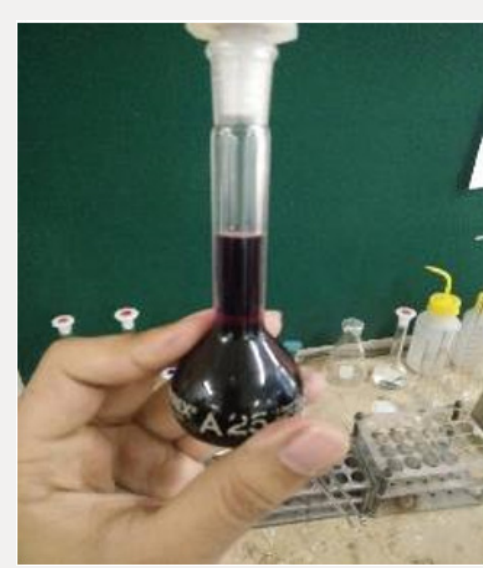

Figure 18: DPPH Stock Solution.

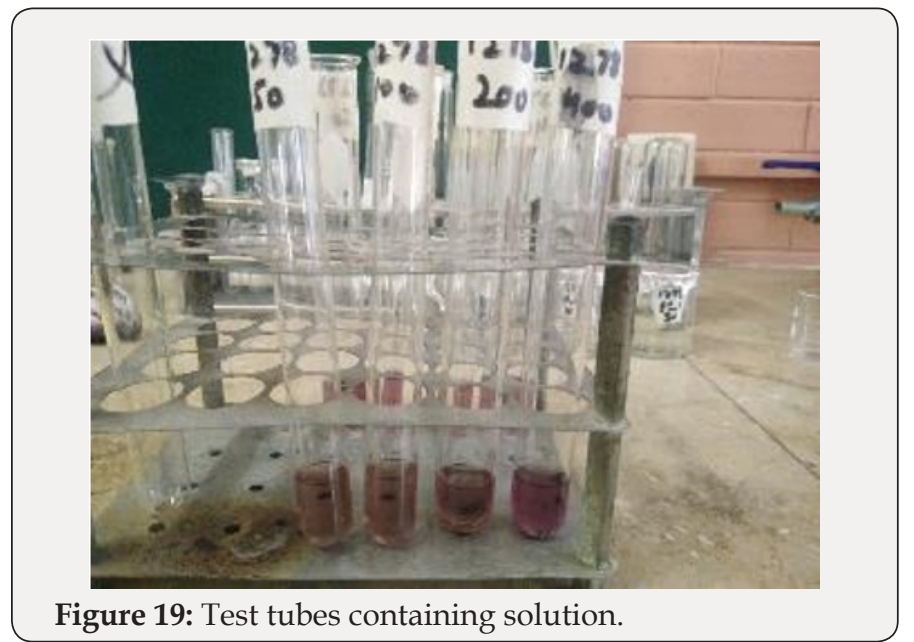

Sensory evaluation of these functional date bars was done for color, taste, flavor, texture and overall acceptability by a panel consisting of 5 judges male and female of different age groups and background. Sample were presented in successions and panelist were asked to rate evaluation variables according to 9-point. Hedonic scale (1=dislike extremely and 9= like extremely) (Figures 15-19).

\section{Proximate Analysis of Functional Date Bars:}

The proximate analysis of functional date bars include moisture, ash, fat, crude fiber was carried out according to standard methods of AOAC (2010).

\section{Determination of Total Polyphenol Content:}

Polyphenol content of functional date bars were determined by the same method as determined from carrot pomace powder which has been described above.

\section{Extraction of Polyphenols from Functional Date Bars:}

Procedure for extraction of polyphenols from functional date bars is same as extraction of polyphenols in carrot pomace powder which has been described above.

\section{Determination of Antioxidant Activity of Functional Date Bars:}

Procedure for determination of antioxidant activity from functional date bars is same as determination of antioxidant activity from carrot pomace powder which has been described above.

\section{References}

1. https://www.sciencedirect.com/topics/agricultural-and-biologicalsciences/polyphenol

2. MT Lee, WC Lin,B Yu, TT Lee (2017) Antioxidant capacity of phytochemicals and their potential effects on oxidative status in animals - A review. Asian-Australas J Anim Sci 30(3): 299-308.

3. https://www.researchgate.net/profile/Arvind_Singh56/post/ Does_animal_matter_decompose_faster_than_the_plant_matter/ attachment/59d62ada79197b80779893df/AS:340839160139780@14 58273796218/download/Decomposition.pdf

4. https://www.teaclass.com/lesson_0301.html

5. Daniel Hinojosa Nogueira, Joaquín Muros, José A Rufián Henares, Silvia Pastoriza (2017) New Method to Estimate Total Polyphenol Excretion: Comparison of Fast Blue BB versus Folin-Ciocalteu Performance in Urine. J Agric Food Chem 65(20): 4216-4222.

6. http://frenchscout.com/polyphenols

7. http://shodhganga.inflibnet.ac.in/bitstream/10603/37756/3/012_ chapter\%202.pdf

8. Gironi F, Piedmont V (2011) Temperature and solvent effects on polyphenol extraction process from chestnut tree wood. Chemical Engineering Research \& Design 89(7A): 857-862.

9. http://tolweb.org/treehouses/?treehouse_id=4615
(C) (P) This work is licensed under Creative

To Submit Your Article Click Here:

Submit Article

DOI: 10.32474/LOJMS.2018.02.000138

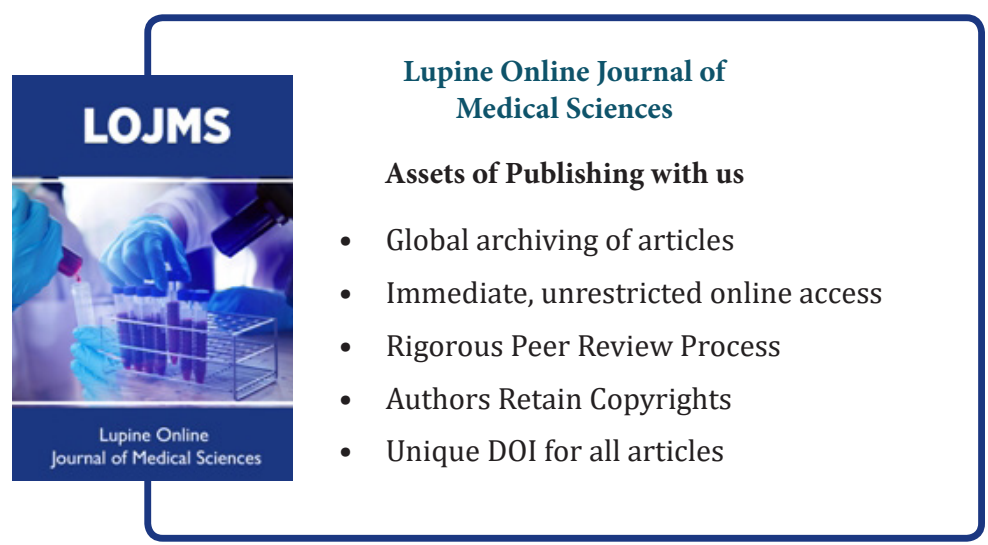

